
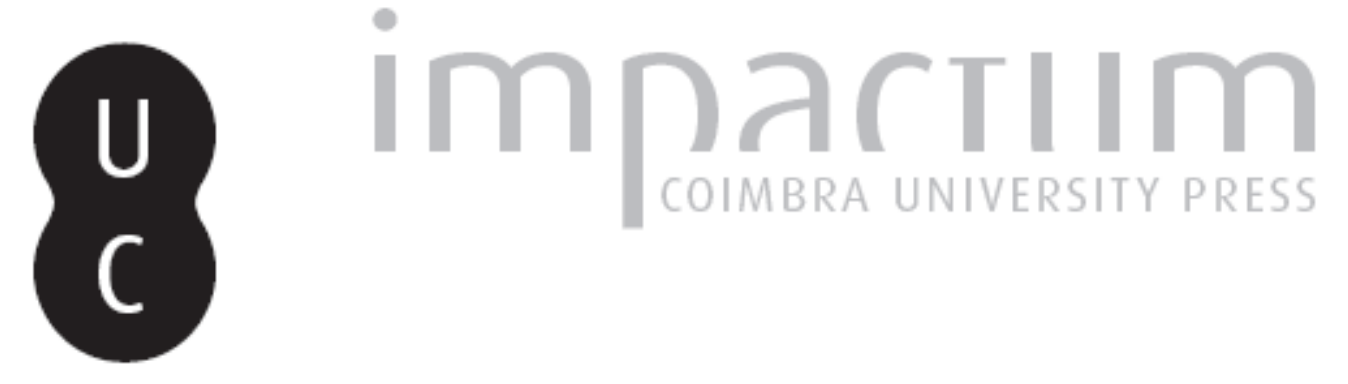

\title{
Fatores condicionantes dos processos erosivos na sub-bacia hidrográfica de Água de Gato - Cabo Verde
}
Autor(es): Vieira, António
URL persistente:
URI:http://hdl.handle.net/10316.2/41209
DOI:
DOI:https://doi.org/10.14195/1647-7723_24_4

Sanches, Filipe Gomes; Carvalho, Ineida Romi Tavares Varela de;
Publicado por:
Associação Portuguesa de Riscos, Prevenção e Segurança; Imprensa da Universidade de Coimbra

Accessed : $\quad$ 26-Apr-2023 13:01:38

A navegação consulta e descarregamento dos títulos inseridos nas Bibliotecas Digitais UC Digitalis, UC Pombalina e UC Impactum, pressupõem a aceitação plena e sem reservas dos Termos e Condições de Uso destas Bibliotecas Digitais, disponíveis em https://digitalis.uc.pt/pt-pt/termos.

Conforme exposto nos referidos Termos e Condições de Uso, o descarregamento de títulos de acesso restrito requer uma licença válida de autorização devendo o utilizador aceder ao(s) documento(s) a partir de um endereço de IP da instituição detentora da supramencionada licença.

Ao utilizador é apenas permitido o descarregamento para uso pessoal, pelo que o emprego do(s) título(s) descarregado(s) para outro fim, designadamente comercial, carece de autorização do respetivo autor ou editor da obra.

Na medida em que todas as obras da UC Digitalis se encontram protegidas pelo Código do Direito de Autor e Direitos Conexos e demais legislação aplicável, toda a cópia, parcial ou total, deste documento, nos casos em que é legalmente admitida, deverá conter ou fazer-se acompanhar por este aviso.
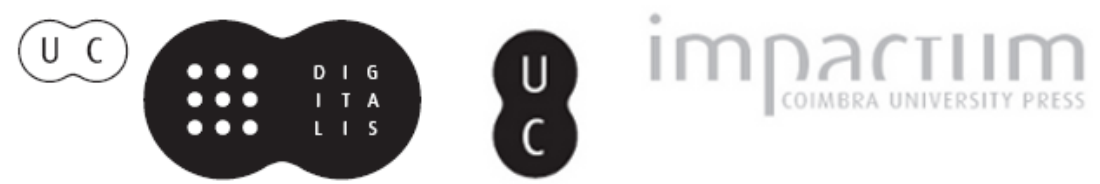


\section{MULTIDISCIPLINARIDADE NA ANÁLISE DAS MANIFESTAÇÕES DE RISCO}

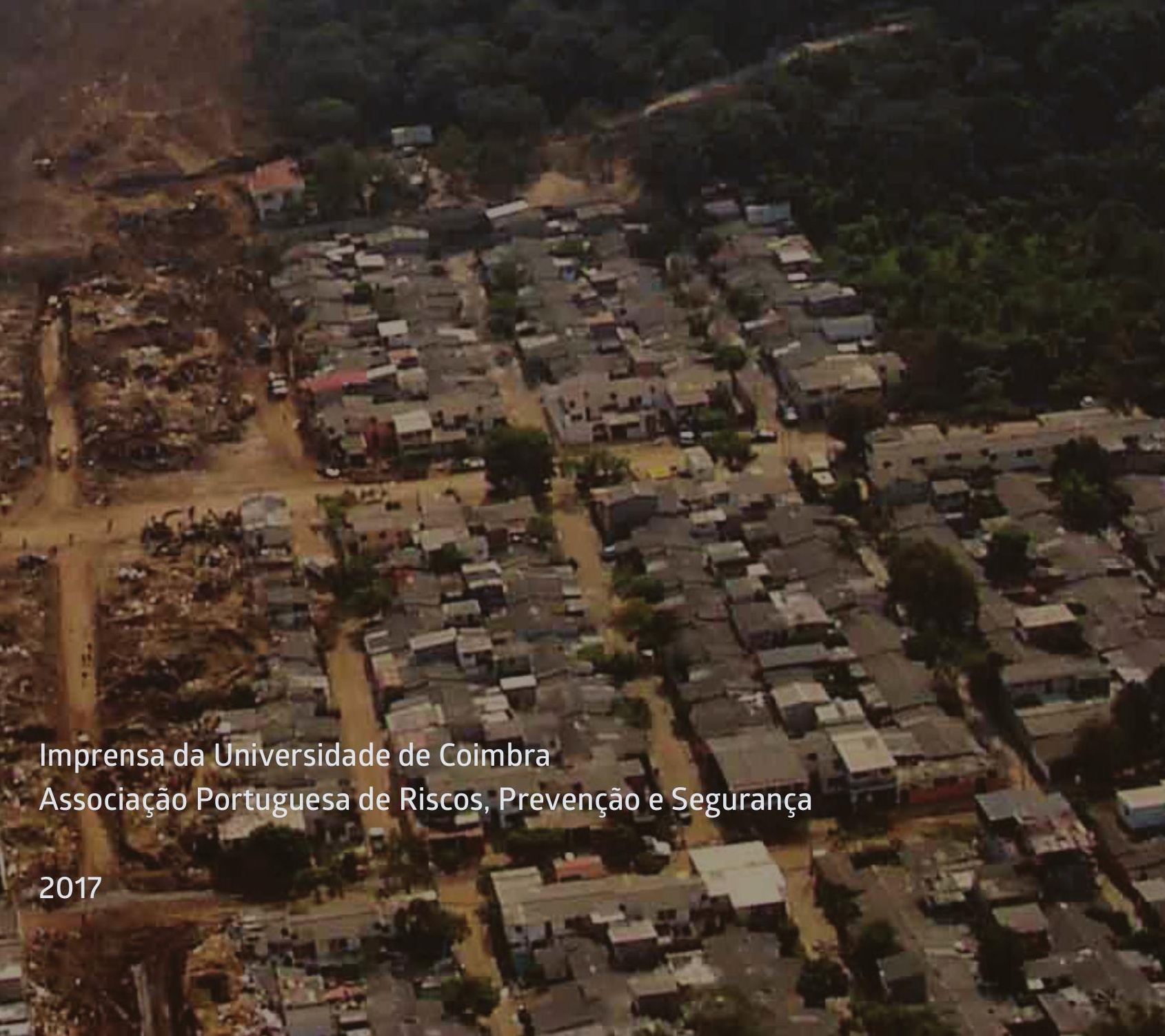




\section{FATORES CONDICIONANTES DOS PROCESSOS EROSIVOS NA SUB-BACIA HIDROGRÁFICA DE ÁGUA DE GATO - CABO VERDE* \\ CONDITIONING FACTORS OF EROSION PROCESSES IN THE SUB-BASIN OF \\ ÁGUA DE GATO - CAPE VERDE - SÃO DOMINGOS MUNICIPALITY, CAPE VERDE}

Filipe Gomes Sanches

Licenciado em Geografia e Ordenamento do Território, Universidade de Cabo Verde filipegsanches@gmail.com

Ineida Romi Tavares Varela de Carvalho

Bolseira da FCG, Doutoranda em Geografia, Universidade de Cabo Verde ineidac@yahoo.com.br

António Vieira

Departamento de Geografia, CEGOT e RISCCOS, Universidade do Minho vieira@geografia.uminho.pt

\section{RESUMO}

O presente trabalho, realizado na Sub-Bacia Hidrográfica de Água de Gato-Concelho de São Domingos, teve como objetivo fundamental o diagnóstico e a aferição dos processos erosivos aí presentes. Os resultados do estudo indiciam que a ocorrência dos processos erosivos na área de estudo não é devida exclusivamente aos processos naturais, sendo que as práticas tradicionais de uso e gestão do solo praticadas nessa área, são significativamente influentes, especialmente por ocorrerem em encostas com declives acentuados e onde estão ausentes práticas adequadas de conservação de solo.

Palavras-chave: Sub-bacia hidrográfica de Água de Gato, diagnóstico, processos erosivos, solo, encostas.

\section{ABSTRACT}

This study, conducted in the sub-basin of Água de Gato - São Domingos municipality, was aimed to diagnose the erosion present in that location. The study results showed that the occurrence of erosion in the study area is not only due to natural processes, or geological/natural erosion, but also to traditional practices of land use and management that is made in this area, in many cases taking place on the hillsides of steep slopes, with absence of soil conservation practices.

Keywords: Sub-basin of Água de Gato, diagnosis, erosion processes, soil, slopes.

\section{RESUMEN}

Factores condicionantes de los procesos erosivos en la sub-cuenca del rio Água de Gato - Cabo Verde - El objetivo de este trabajo hecho en la sub-cuenca del rio Água de Gato-Concelho de São Domingos, fue hacer el diagnóstico de los procesos erosivos allí presentes. Los resultados de este estudio han informado que la ocurrencia de los procesos erosivos en el área de estudio no se debe únicamente a los procesos naturales, sino que también a las prácticas tradicionales de uso y gestión del suelo que es practicado en ese área, donde en muchos casos se da sobre laderas con declives acentuados, con ausencia de prácticas de conservación del suelo.

Palabras clave: Sub-cuenca del rio Água de Gato, diagnóstico, procesos erosivos, suelo, laderas.

\section{RESUMÉ}

Les facteurs qui conditionnent les processus d'érosion dans le sous-bassin de la rivière "Água de Gato", Cap-Vert - L'objectif de cette étude, menée dans le sous - bassin de la rivière "Água de Gato", comté de "Saint-Domingue" (Cap-Vert), est de diagnostiquer les processus d'érosions. Les résultats de l'étude ont montré que ces processus ne sont pas seulement dus à un facteur naturel ('érosion géologique/naturelle) mais découlent aussi à de pratiques traditionnelles d'utilisation et de gestion des terres sans mode de conservation des sols.

Mots-clé: Sous-bassin de la rivière Água de Gato, diagnostic, processus d'érosion, sol, versant.

* O texto deste artigo corresponde a uma comunicação apresentada no III Congresso Internacional, I Simpósio Ibero-Americano e VIII Encontro Nacional de Riscos, tendo sido submetido em 13-06-2015, sujeito a revisão por pares a 18-06-2015 e aceite para publicação em 01-03-2016.

Este artigo é parte integrante da Revista Territorium, n. ${ }^{\circ} 24,2017,{ }^{\circ}$ RIscos, ISSN: 0872-8941. 


\section{Introdução}

O desenvolvimento de fenómenos erosivos decorre da ação de um conjunto de processos dependentes das condições naturais existentes num determinado território. No entanto, a progressiva apropriação dos territórios por parte do Homem, tem contribuído para uma maior influência antrópica naqueles processos, acentuando-os frequentemente.

Com efeito, o clima (especialmente as caraterísticas da chuva), as características das vertentes, a cobertura vegetal e a natureza do solo são fatores importantes (Araújo et al., 2005). A estes fatores, e particularmente no caso de Cabo Verde, associam-se a fraca cobertura vegetal, o remeximento do solo para fins agrícolas e as referidas condições de clima semiárido saheliano, com chuvas concentradas e intensas, que acentuam ainda mais aquela dinâmica (Costa e Nunes, 2008). Como apontam alguns estudos já efetuados (Costa, 2004; Leal, 2008; Tavares, 2010), a problemática da erosão em Cabo Verde é preocupante. De acordo com o Ministério do Ambiente Agricultura e Pescas (2004), em Cabo Verde a perda de solo devido à erosão hídrica e eólica são considerados os problemas agrícolas e ambientais mais críticos. Estima-se em 7,8 ton/ha a perda anual de solo, em regime de agricultura tradicional (milho e feijões). Ainda estudos mais recentes feitos por Tavares e AmiotteSuchet (2012) apontam que na ilha Santiago (onde se encontra a área de estudo) mais de $90 \%$ dos solos estão sob risco de erosão grave. A área objeto deste estudo, uma sub-bacia hidrográfica, possui características que possivelmente favorecem a manifestação dos processos erosivos. A sua morfologia, caraterizada por encostas com declive acentuado, encontra-se sujeita a problemas de erosão. Relacionado com a diversidade do uso e gestão do solo nesta sub-bacia, observa-se que a intervenção do Homem contribui, em muitos casos, para a aceleração dos processos erosivos, através da sobre-exploração do solo e remoção da sua cobertura protetora natural, bem patente na área de estudo em análise, onde a sua presença é intensa não só por nela estarem implantados alguns aglomerados populacionais, mas também pela sua ocupação intensiva por atividades agro-silvo-pastoris.

Neste sentido, pretende-se através deste trabalho identificar processos erosivos ocorridos na sub-bacia hidrográfica de Água de Gato e a influência das atividades antrópicas no seu desenvolvimento.

\section{Caracterização da área de estudo}

A sub-bacia hidrográfica de Água de Gato (SBHAG), com uma superfície de drenagem de 3,54 km² e 9,07 km de perímetro, localiza-se na região noroeste do Concelho de São Domingos, um dos concelhos da Itha de Santiago Cabo Verde (fig. 1), mais concretamente nas cabeceiras da bacia hidrográfica de São Domingos (Sanches, 2012). No que diz respeito à geomorfologia, a SBHAG apresenta uma diversidade de formas de relevo, desde os mais expressivos, constituídos por picos, na parte sul e noroeste da mesma, às encostas onduladas um pouco por toda a sub-bacia, até aos níveis planos na zona central e foz da sub-bacia (Faria, 1970).

Quanto a geologia, de acordo com a carta Geológica da Itha de Santiago (Serralheiro et al., 1976), afloram na área de estudo as seguintes formações: o Complexo Filoniano de Base (CA), que se encontra enquadrado no complexo eruptivo interno, antigo, de natureza essencialmente basáltica, corresponde às formações mais antigas da parte emersa da ilha (Serralheiro et
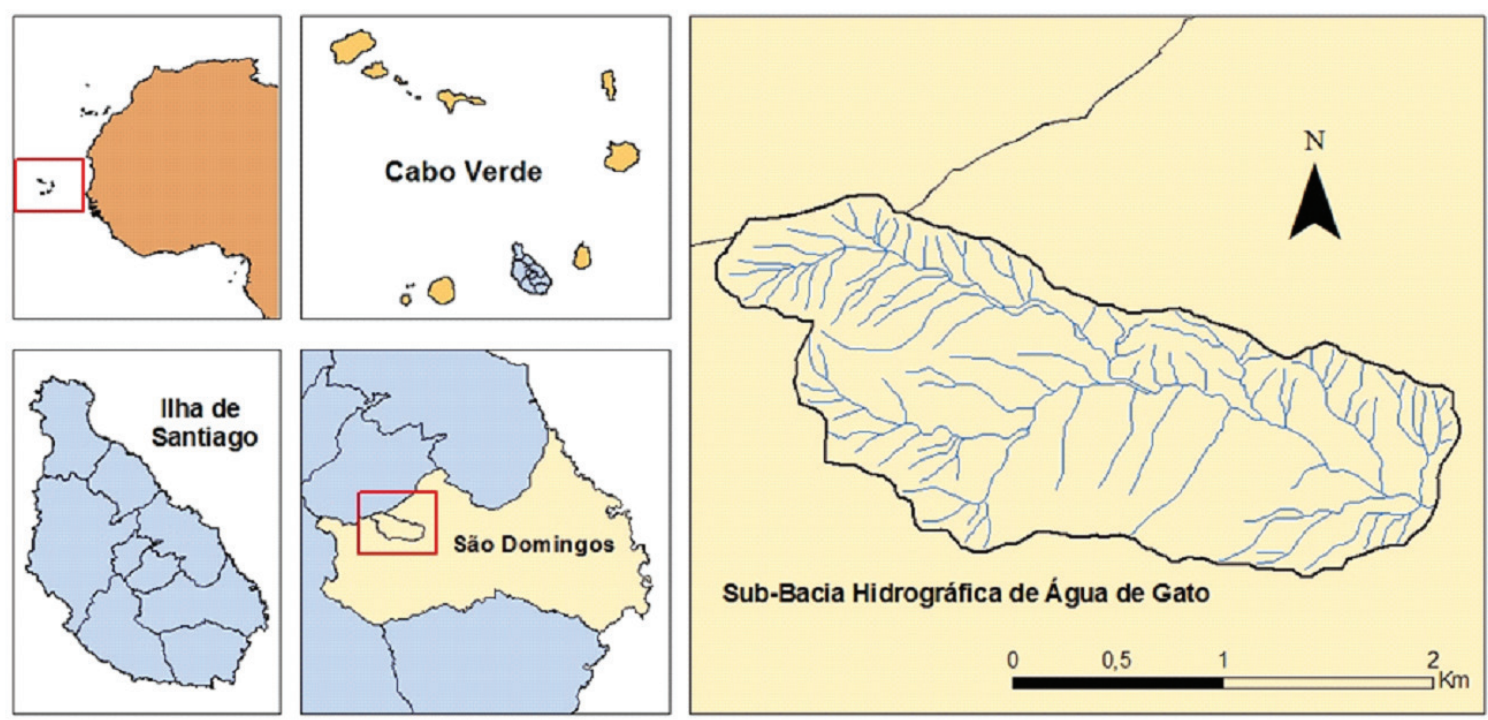

Fig. 1 - Localização geográfica da SBHAG no contexto da ltha de Santiago e Concelho de São Domingos (Fonte: DGHOT).

Fig. 1 - Geographical location of the SBHAG in the context of Santiago Island and the municipality of Santo Domingo (Source: DGHOT). 
al., 1976). Estas formações, em geral muito alteradas, são as predominantes no Complexo eruptivo Interno antigo. A Formação dos Órgãos (CB) corresponde a formações do Miocénico (Serralheiro et al., 1976), que se encontram numa fase de intensa alteração. Esta formação é constituída por unidades muito espessas, de elementos angulosos, subangulosos e arredondados, por vezes com superfícies bem polidas. A Formação dos Órgãos é complexa e heterogénea, inclui intercalações arenosas e puramente conglomerátícas e, embora escassamente, são conhecidos episódios lávicos na sua sequência (Hernández, 2008, p.40). O Complexo eruptivo de Pico da Antónia (PA) abrange a maior parte da área aflorante da ilha (Serralheiro et al., 1976), e integra essencialmente mantos basálticos. As rochas do Complexo eruptivo do Pico da Antónia (PA) são responsáveis pelas maiores altitudes do relevo e, também, pelos planaltos estruturais do sector oriental e meridional (Hernández, 2008, p.43). Ocorrem ainda, na ilha de Santiago, formações de idade quaternária, de génese terrestre e marinha, correspondentes a aluviões antigas e modernas. Constituem essencialmente terraços, depósitos de vertente, de enxurrada, areias de duna e praias marinhas em vários níveis até $100 \mathrm{~m}$ de altitude (Serralheiro et al., 1976, citado por Hernández, 2008, p.48).

\section{Metodologia}

Este trabalho de pesquisa foi desenvolvido em diversas fases. Numa primeira fase realizou-se um aturado trabalho de pesquisa bibliográfica, que se focalizou na recolha de documentos que abordam a problemática de erosão dos solos, por forma a oferecer uma adequada base conceptual, bem como o levantamento de dados relativos aos elementos físicos e humanos presentes na área de estudo, com vista à sua caraterização e enquadramento. A segunda fase correspondeu ao trabalho de campo, que decorreu na SBHAG, e privilegiou a observação direta do território, de modo a fazer o reconhecimento da área de estudo, e o levantamento de dados ambientais (relativos aos solos, vegetação, entre outros), tendo-se também procedido à identificação de diversos tipos de formas e processos de erosão na área de estudo e observação de alguns fatores atuantes nos processos erosivos. No decurso do trabalho de campo procedeu-se, também, à amostragem de solos. Para este efeito foram feitas recolhas a uma profundidade média de $20 \mathrm{~cm}$, tendo no total sido recolhidas 46 amostras de solos (fig. 2). Nos pontos alvo de amostragem foram levantados diversos parâmetros, como as coordenadas geográficas, a orientação das encostas, o perfil de encosta, as espécies e tipos de arborização, o declive, a percentagem do coberto vegetal, entre outros parâmetros necessários para a rigorosa caraterização dos pontos de amostragem. Após a recolha, as amostras de solo foram encaminhas para o laboratório e feita a secagem dos mesmos, para posterior análise. A terceira fase consistiu na realização de análises laboratoriais das amostras de solo recolhidas e produção e análise cartográfica da área de estudo. As análises dos solos foram realizadas no Laboratório de análise de solos, água e plantas (LASAP) do Instituto Nacional de Investigação e Desenvolvimento Agrário (INIDA), em São Jorge dos Órgãos, Ilha de Santiago, e compreenderam a análise da Matéria Orgânica e Textura. Para as análises da textura utilizou-se o método gravimétrico. Na determinação da matéria orgânica utilizou-se o método Walkley-Black.

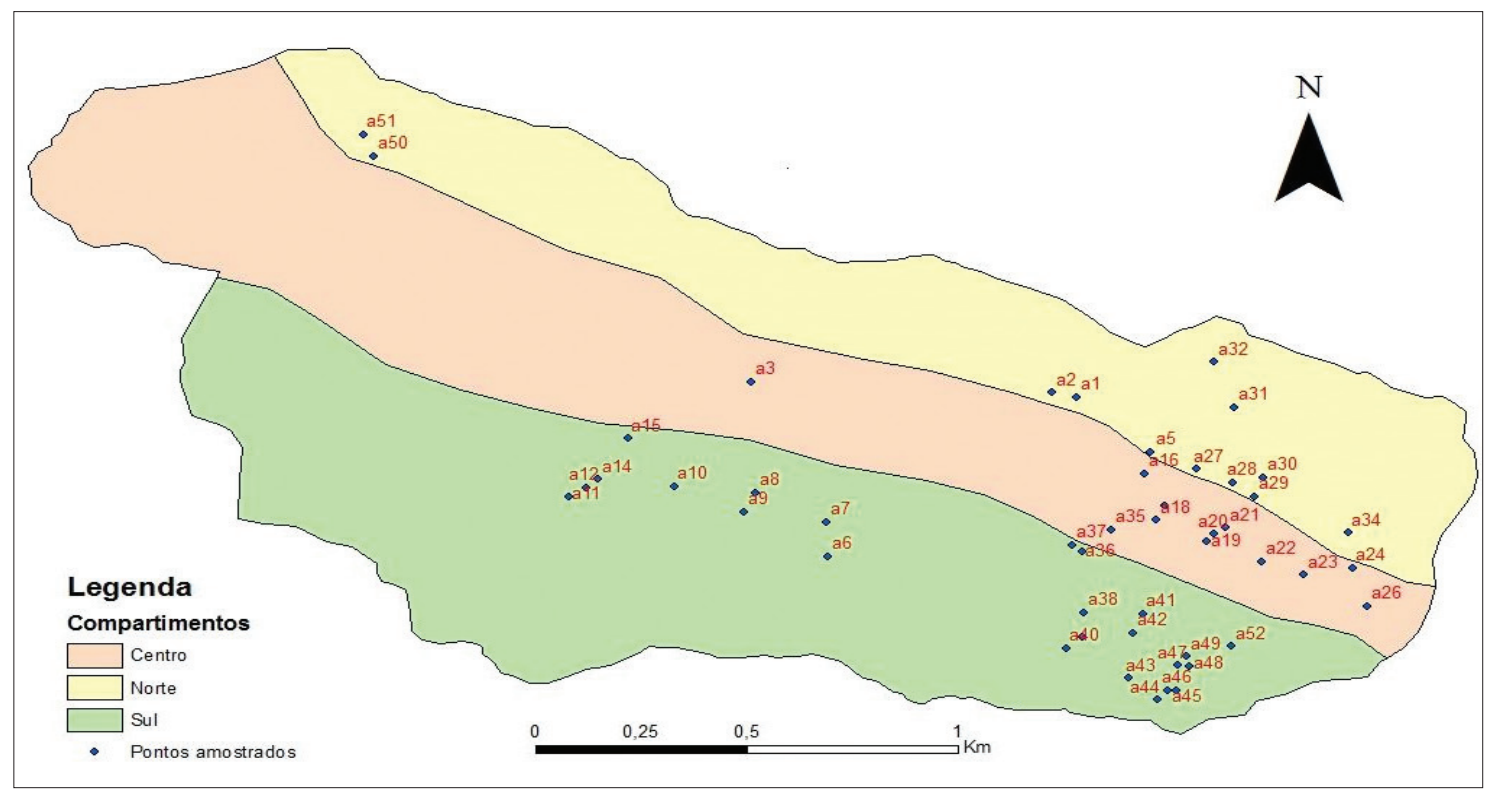

Fig. 2 - Distribuição dos locais de recolha das amostras de solos nos três compartimentos da área de estudo.

Fig. 2 - Distribution of soil sample points in the three compartments of the study area. 


\section{Resultados e discussão}

A análise desenvolvida ao longo deste trabalho pretendeu evidenciar alguns dos fatores envolvidos na ocorrência de processos erosivos ao longo das vertentes da SBHAG. Para atingirmos este objetivo, procedemos à caraterização da precipitação na área de estudo, procurando avaliar a sua capacidade erosiva, à análise da distribuição dos declives e da vegetação, bem como das formas de uso do solo e técnicas de conservação implementadas. Procedeuse, também, à caraterização de alguns parâmetros do solo, nomeadamente a sua textura e a matéria orgânica, através da análise de amostras de solo recolhidas na área de estudo.

\section{Precipitação}

Á semelhança das outras ilhas do arquipélago caboverdiano, em Santiago a precipitação concentra-se nos meses de Julho a Outubro, assistindo-se a uma elevada variabilidade anual. A precipitação ocorre normalmente de modo intenso e concentrado, num curto período de tempo, provocando grande escorrência (Amaral, 1964; Ferreira, 1986; Correia, 1998; Costa, 2004).

Analisando os dados pluviométricos do posto de Lém Pereira (localizado na área de estudo), verifica-se que na SBHAG o seu comportamento é similar, ou seja, a precipitação concentra-se em poucos meses do ano (fig. 3), com carácter intenso, traduzindo-se num fator atuante no processo de erosão dos solos.

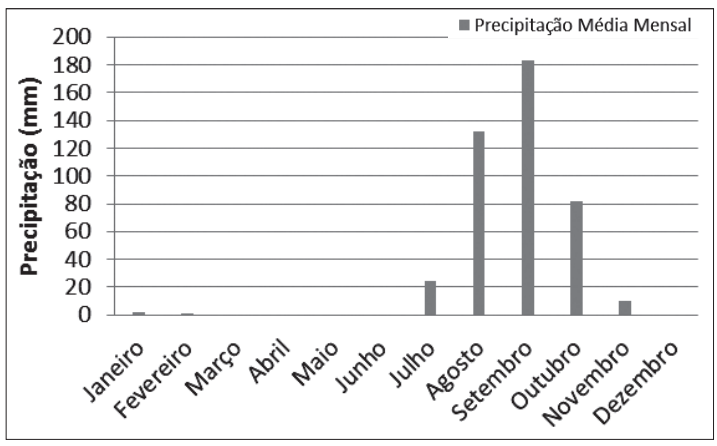

Fig. 3 - Variação da média mensal no período de 2001 a 2010. Fonte: Instituto Nacional de Meteorologia e Geofísica, posto Lém Pereira.

Fig. 3 - Variation of the monthly average, from 2001 to 2010. Source: National Institute of Meteorology and Geophysics.

Para análise da intensidade da erosividade de precipitação dos meses mais pluviosos (Agosto, Setembro e Outubro) no período de 2008 a 2010, aplicou-se o Índice de Fournier modificado (de acordo com a metodologia utilizada no projeto DESIRE, 2008, citado por Tavares, 2010), aos dados de precipitação ( $\mathrm{mm}$ ) correspondentes ao posto de Lém Pereira, São Domingos. A equação utilizada no projeto DESIRE (2008, citado por Tavares,
2010) que nos permite determinar a erosividade mensal é seguinte:

$$
F i_{\text {DESIRE }}=\sum_{i=1}^{12} P_{i}^{2} / p
$$

Em que:

$$
\begin{aligned}
& \mathrm{Fi}=\text { Índice de Fournier modificado } \\
& \mathrm{Pi}=\text { acumulação mensal }(\mathrm{mm}) \\
& \mathrm{p}=\text { acumulação anual. }
\end{aligned}
$$

Conforme classificação feita por DESIRE (2008) a agressividade da chuva é expressa nas seguintes classes (TABELA I):

TABela I - Classificação de intensidade de erosividade. TABLE I - Erosion intensity classification.

\begin{tabular}{|c|c|}
\hline Descrição & Classes \\
\hline Muito Fraco & $<60$ \\
\hline Fraco & $60-90$ \\
\hline Moderada & $91-120$ \\
\hline Forte & $121-160$ \\
\hline Muito Forte & $>160$ \\
\hline
\end{tabular}

Fonte: DESIRE (2008). Source: DESIRE (2008).

Com base nesta classificação, e tendo em conta os resultados obtidos com a aplicação da equação acima referida aos dados correspondentes à precipitação ocorrida nos meses mais pluviosos entre os anos 2008 e 2010, verificamos que os valores que expressam maior erosividade correspondem aos relativos aos meses de Setembro de 2009 e Setembro de 2010 (TABELA II), ou seja, para esses meses os valores de erosividade enquadram-se na classe de forte erosividade.

Com efeito, com base no trabalho de Ferreira (1987), relativo à precipitação registada na estação de S. Jorge dos Órgãos, para o período de 1963 a 1978, constata-se que foi o mês de setembro o que registou maior número de dias com ocorrência de precipitação superior a $50 \mathrm{~mm}$ e $100 \mathrm{~mm}$.

Declives como um dos fatores potenciadores dos processos erosivos na área de estudo

No âmbito deste trabalho procedemos, também, à análise dos declives, seguindo a proposta de Lepsch et al. (1991, citado por Costa et al., 2009), definindo 6 classes de declive, e procurando identificar a correlação das diferentes classes de declive com o processo da erosão dos solos. 
TABela II - Erosividade dos três meses mais pluvioso do ano (Agosto, Setembro e Outubro), na SBHAG, segundo o índice de Fournier modificado (DESIRE, 2008).

TABLE II - Erosion of the three rainiest months of the year (August, September and October), in the SBHAG, following the modified Fournier Index (DESIRE, 2008).

\begin{tabular}{|c|c|c|c|c|}
\hline \multirow[b]{2}{*}{ Anos } & \multirow[b]{2}{*}{ Meses } & \multicolumn{3}{|c|}{ Sub-Bacia de Água de Gato } \\
\hline & & $\begin{array}{l}\text { Acumulação Mensal } \\
(\mathrm{mm})\end{array}$ & $\begin{array}{l}\text { Acumulação Anual } \\
(\mathrm{mm})\end{array}$ & Erosividade (Fi) \\
\hline \multirow{3}{*}{2008} & Agosto & 155,5 & \multirow{3}{*}{440,2} & 55 \\
\hline & Setembro & 116 & & 31 \\
\hline & Outubro & 82,2 & & 15 \\
\hline \multirow{3}{*}{2009} & Agosto & 153,4 & \multirow{3}{*}{609,4} & 37 \\
\hline & Setembro & 297,7 & & 145 \\
\hline & Outubro & 158,3 & & 41 \\
\hline \multirow{3}{*}{2010} & Agosto & 124 & \multirow{3}{*}{577,8} & 27 \\
\hline & Setembro & 270,5 & & 127 \\
\hline & Outubro & 183,3 & & 58 \\
\hline
\end{tabular}

As áreas planas, com declividade de 0 a $3 \%$ e de 3 a $6 \%$ (fot. 1), representam uma pequena percentagem da área da sub-bacia estudada, totalizando $0,18 \mathrm{~km}^{2}(5,1 \%) \mathrm{da}$ área total. Para Lepsch et al. (1991, citado por Costa et al., 2009), essas áreas são indicadas para a plantação de culturas anuais, com o uso de práticas simples de conservação do solo.

As áreas com relevo ondulado, com declives entre $6 \mathrm{e}$ $12 \%$, abrangem $0,59 \mathrm{Km}^{2}(16,76 \%)$ da área total, e são indicadas para a plantação de culturas anuais, sendo recomendadas práticas de conservação do solo (Lepsch et al., 1991 citado por Costa et al., 2009).

Os declives entre os 12 e $20 \%$, relativos a um relevo forte ondulado (fot. 2), estendem-se por grande parte da SBHAG, representando $38,35 \%\left(1,35 \mathrm{Km}^{2}\right)$ da área total. São áreas onde se verifica uma ocorrência significativa de problemas relacionados com erosão, consequentemente, impróprias para culturas anuais e indicadas para culturas perenes, por forma a proporcionar uma proteção mais eficaz do solo (Lepsch et al., 1991 citado por Costa et

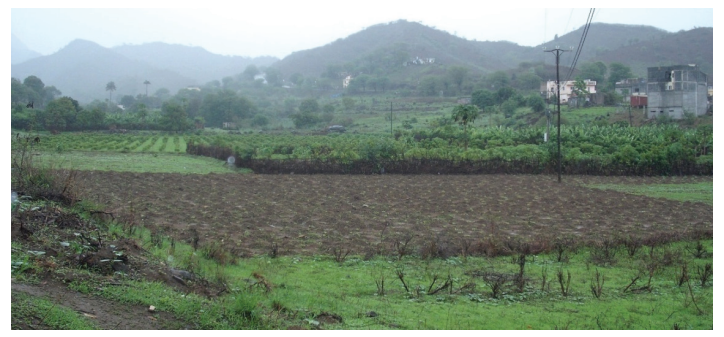

Fot. 1 - Planície aluvional próxima da foz (este) da Sub-Bacia. (Fonte: F. Sanches, 2012).

Photo 1 - Alluvial plain near the mouth of the sub-basin (Source: F. Sanches, 2012), al., 2009). Na área de estudo essas áreas são utilizadas, na sua maioria, na agricultura de sequeiro, ou seja, são ocupadas com cultivos anuais.

Para a classe de declives de 20 a 45\%, classificada como relevo montanhoso, identificamos também uma grande parte da área estudada, constituindo $36,93 \%\left(1,3 \mathrm{Km}^{2}\right)$ da área total, e verificamos como se encontram sujeitas a erosão, multiplicando-se os exemplos da atuação de processos erosivos e movimentos de vertente associados (escoadas e desabamentos).

Para a classe de declives superiores a 45\%, classificada como relevo escarpado, conforme os já referidos autores, apenas identificamos uma área de $0,1 \mathrm{Km}^{2}(2,84 \%) \mathrm{da}$ área total, que se encontra localizada sobretudo na parte centro oeste e sul da sub-bacia em estudo (fig. 4).

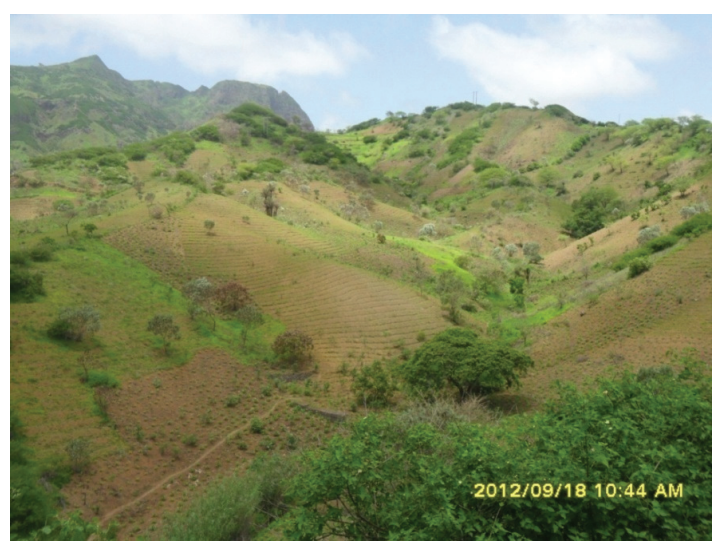

Fot. 2 - Paisagem Ilustrativa de relevo ondulado na parte norte de SBHAG (Pinha) (Fonte: F. Sanches, 2012).

Photo 2 - Illustrative landscape of the undulating relief in the northern part of SBHAG (Pinha) (Source: F. Sanches, 2012). 


\section{Vegetação}

Entre os principais efeitos da cobertura vegetal, Bertoni e Lombardi Neto (1985, citado por Salomão, 2007, p.232) destacam os seguintes: a) proteção contra o impacto das gotas de chuva; b) dispersão e quebra da energia das águas de escoamento superficial; c) aumento da capacidade de retenção de água pela estruturação do solo por efeito da produção e incorporação de matéria orgânica.

Em relação à presença de vegetação arbórea na área de estudo, em muitos casos ela encontra-se bastante rarefeita e em alguns casos a inexistência da vegetação deixa os solos expostos aos processos erosivos (fot. 3 ).

No caso da área em estudo, o material vegetal restante das culturas é aproveitado pelos agricultores como forragem para os animais. Segundo Tavares et al. (2012), o solo fica duplamente empobrecido: por um lado, porque as culturas absorvem uma quantidade importante dos nutrientes do solo para o seu crescimento, desenvolvimento e produção de grãos e, por outro lado, o solo não recebe nenhuma forma de compensação de fertilizantes nem de restituição de material vegetativo por parte dos usuários da terra. Portanto, a conjugação destes factos conduz a uma progressiva degradação do solo, com uma consequente redução do grau de fertilidade e fazendo com que fique sujeito à agressividade das chuvas e à erosão, que remove, a cada ano, uma parte muito significativa do material do solo, em particular o material mais leve e fino, tornando, desta forma, o teor em matéria orgânica e argila fraca.

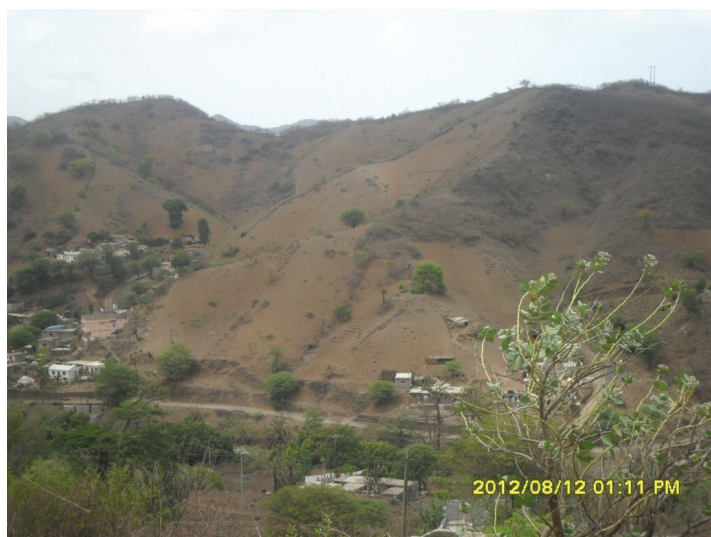

Fot. 3 - Solo exposto aos processos erosivos na zona de Lém Pereira (Fonte: F. Sanches, 2012).

Photo 3 - Soil exposed to erosion in Lem Ferreira's area (Source: F. Sanches, 2012).

Uso, gestão e ocupação do Solo na sub-bacia de Água de Gato

Nas regiões semiáridas do mundo, é comum o emprego da agricultura de sequeiro em áreas de relevo movimentado, principalmente nas encostas, durante o período chuvoso, e da pequena agricultura irrigada de base familiar, nos vales aluviais (como se verifica na área de estudo) (Sousa, Oliveira e Oliveira, 2012).

Constatou-se que a aceleração dos processos erosivos na área em estudo, em muito casos, está associada aos usos inadequados dos solos que se faz em zonas declivosas.

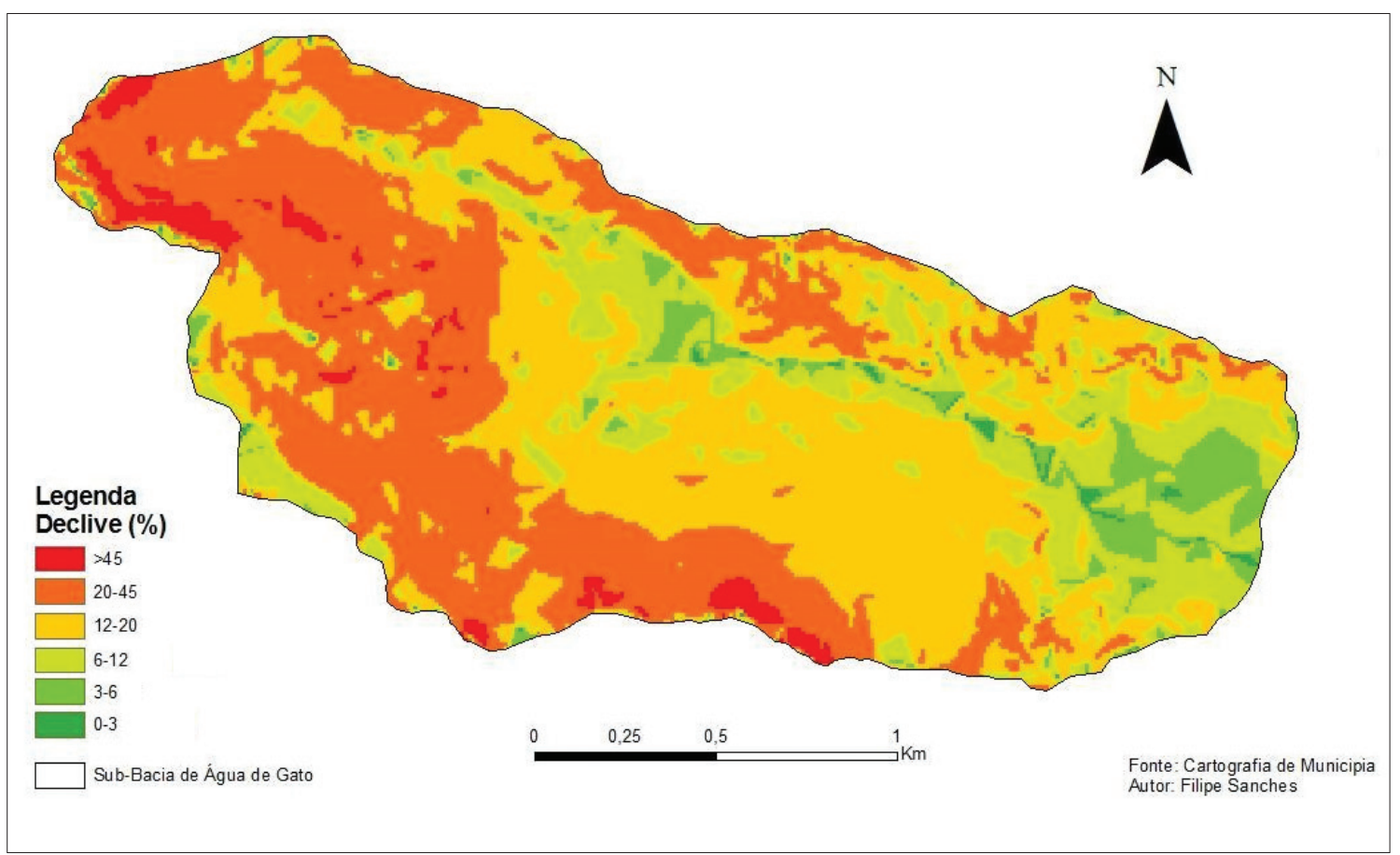

Fig. 4 - Carta de declives da SBHAG - Concelho de São Domingos.

Fig. 4 - Map of slopes of the SBHAG - São Domingos municipality. 
A morfologia dessas encostas não é adequada a determinados tipos de uso do solo que aí ocorrem, como por exemplo cultura em camalhões e "monda" (capina), que é feita com intuito de eliminar manualmente as ervas daninhas que se desenvolvem à volta das culturas de milho e feijão (fot. 4). Conforme referem Tavares et al. (2012), as práticas de capina com enxada, como as que observamos na área de estudo, podem mobilizar o solo até $7,0 \mathrm{~cm}$ de profundidade (a mais rica em matéria orgânica), de cima para baixo nas encostas, reduzindo a estabilidade do solo, especialmente na primeira capina, que é a mais degradante para o solo

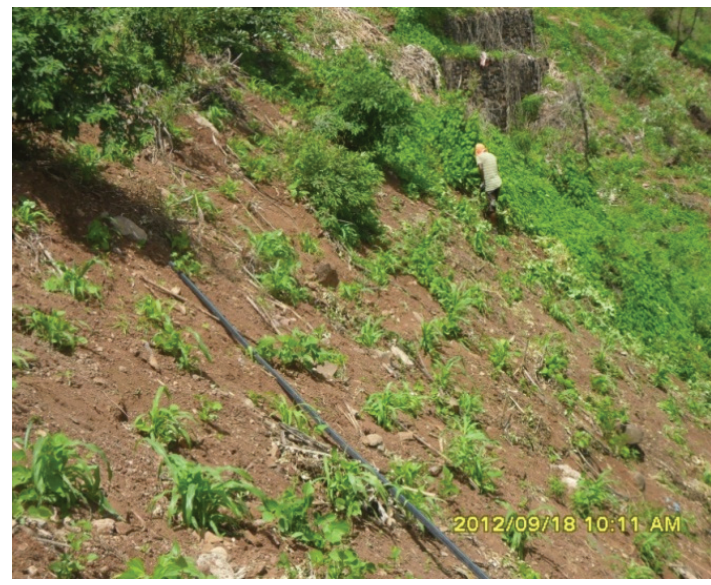

Fot. 4 - Prática de monda numa encosta declivosa na zona de Réma-Réma (Fonte: F. Sanches, 2012).

Photo 4 - Weeding practice in a steep slope at Réma-Réma's zone (Source: F. Sanches, 2012).

O cultivo em forma de camalhões é bastante comum nas encostas da sub-bacia de Água de Gato. Os solos que se encontram sob essa forma de cultivo sofrem alterações significativas (fot. 5) e perante uma forte precipitação geram-se com muita facilidade fluxos de lama e detritos. Carvalho (2009) chama a atenção para o facto de que "[...] a cultura em camalhões traz impactos graves para o ambiente, isso porque depois da colheita do amendoim o solo permanece desprotegido. Quando chove, dá-se o impacto direto das gotas de água sobre o solo, levando à desagregação e movimentação de partículas do solo, sobretudo para o fundo dos vales, que por sua vez, são arrastados pelas cheias $e$ transportados para lugares distantes, provocando o assoreamento dessas zonas [...] ".

O uso antrópico na sub-bacia em estudo é significativo, com especial destaque para a ocupação de zonas declivosas (fot. 6 e 7). De acordo com Carvalho (2009), é comum que ocorram movimentos de vertente nessas áreas, potencializados pela ação antrópica, muitas vezes mobilizando materiais produzidos pela própria ocupação (depósitos de entulho, resíduos sólidos, entre outros).

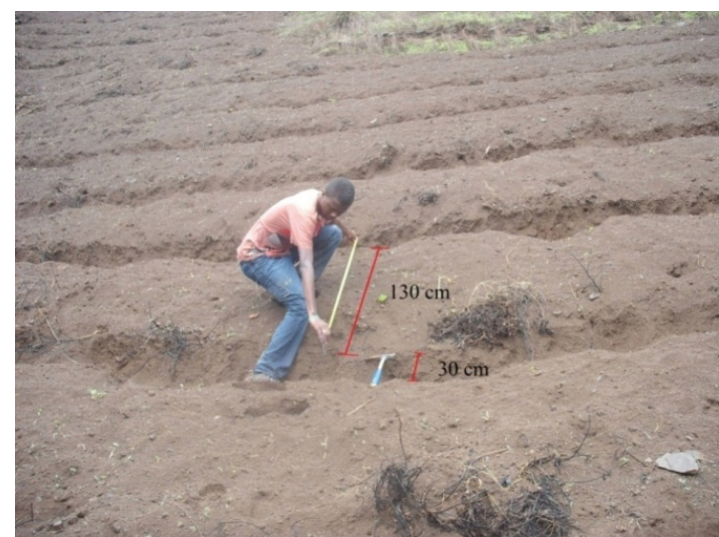

Fot. 5 - Cultura em forma de camalhões nas encostas de Pinha (Fonte: F. Sanches, 2012).

Photo 5 - Agriculture in ridges on Pinha's slopes (Source: F. Sanches, 2012).

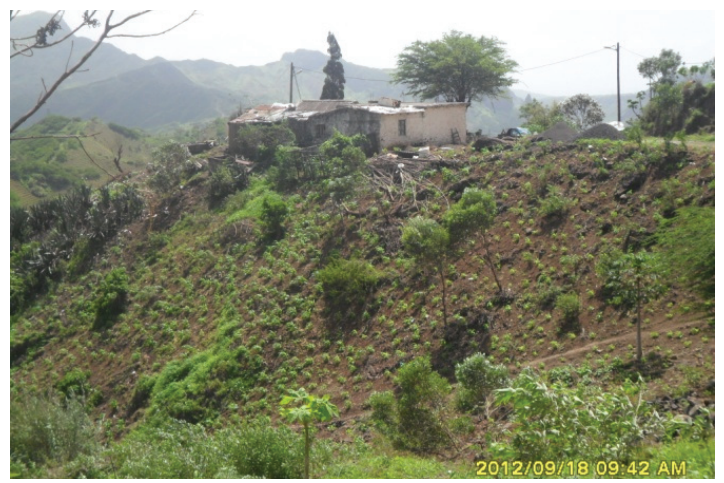

Fot. 6 - Ocupação antrópica generalizada das encostas na zona de Réma-Réma (Fonte: F. Sanches, 2012).

Photo 6 - Widespread anthropic occupation of slopes at RémaRéma's zone (Source: F. Sanches, 2012).

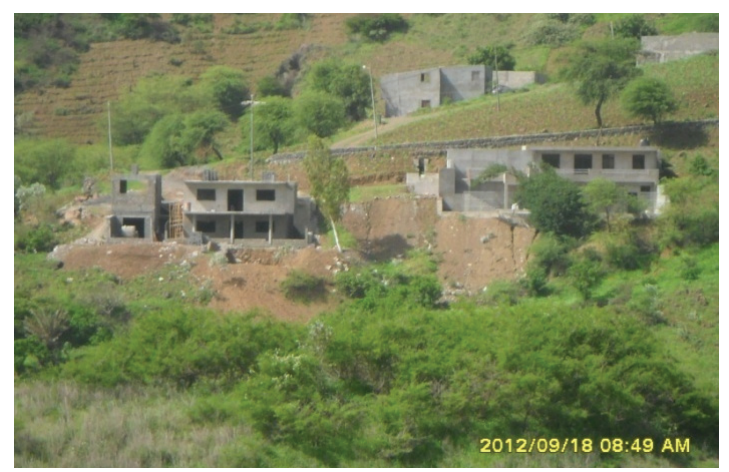

Fot. 7 - Ocupação antrópica generalizada nas encostas da zona de Caiada (Fonte: F. Sanches, 2012).

Photo 7 - Widespread anthropic occupation of slopes at Caiada's zone (Source: F. Sanches, 2012).

Técnicas de conservação do solo existentes na sub-bacia de Água de Gato

A implementação de técnicas de conservação dos solos é fundamental para evitar o desencadeamento de processos erosivos nas vertentes. $\mathrm{Na}$ área estudada observa-se a implementação de algumas obras de 
conservação do solo, como seja a construção de muros de proteção, diques (fot. 8) e arretos (fot. 9) que, no entanto, revelaram ser ineficazes no que diz respeito à conservação do solo. Isto porque, com o passar do tempo, este tipo de infraestrutura de conservação se desmantela com relativa facilidade, deixando de ser uma barreira de impedimento ao transporte do solo. Portanto, para além de serem limitadas, precisam de manutenções frequentes para poderem continuar a desempenhar as funções para as quais foram implementadas.

\section{Propriedades dos solos amostrados}

Os solos possuem propriedades físicas e químicas que interagem e podem proporcionar maior ou menor resistência aos processos erosivos (Guerra e Botelho, 1996). Neste estudo foram analisadas propriedades como

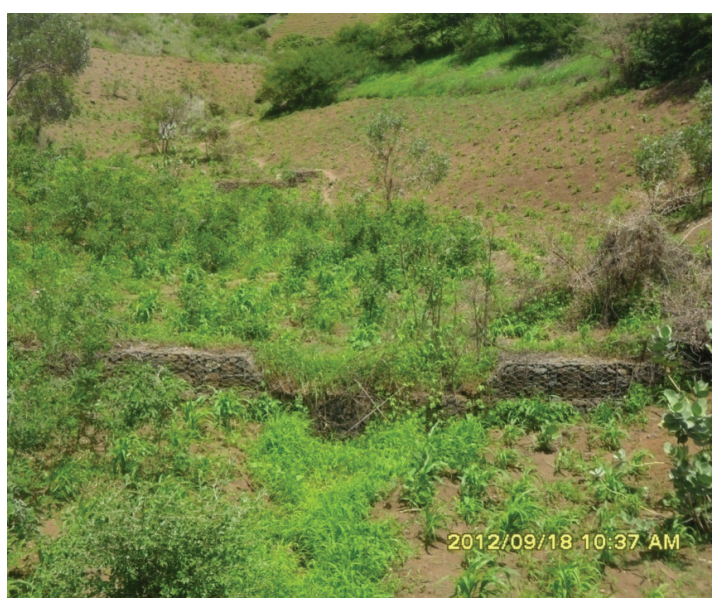

Fot. 8 - Pequeno dique de contenção da erosão na zona de Pinha (Fonte: F. Sanches, 2012).

Photo 8 - Small erosion containment dike at Pinha's zone (Source: F. Sanches, 2012).

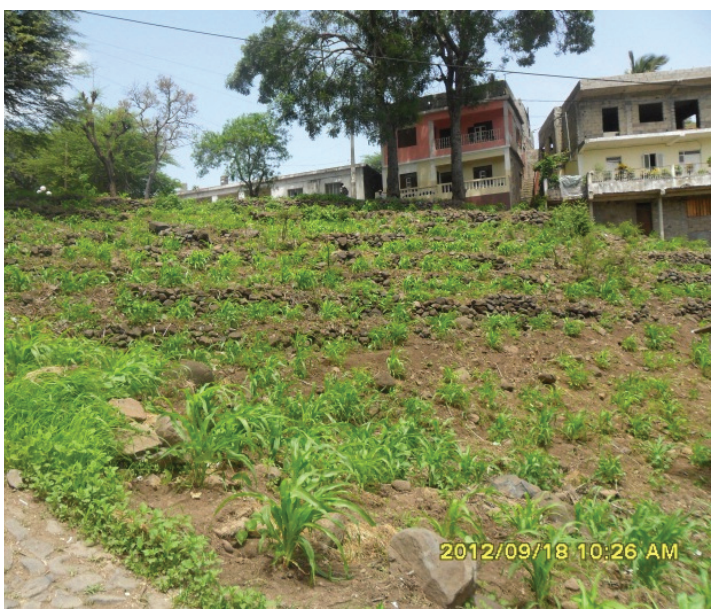

Fot. 9 - Arretos de contenção da erosão pouco eficaz na zona Lém Pereira (Fonte: F. Sanches, 2012).

Photo 9 - Ineffective small erosion containment walls at Lém Pereira's zone (Source: F. Sanches, 2012). a textura e a matéria orgânica dos solos, tendo em conta 46 pontos de recolha de amostras distribuídos pela área da sub-bacia em análise (fig. 2).

No que diz respeito à textura, das 46 amostras de solo analisadas, segundo a classificação feita pelo Laboratório de Análise de Solos Água e Planta do Instituto Nacional de Investigação e Desenvolvimento Agrário (INIDA), 22 apresentaram textura limosa, 21 franco limosa e 3 apresentaram textura franco-argila-limosa (TABELA III).

Segundo Guerra (2007) os solos com maior erodibilidade são aqueles com maior teor de limo, à semelhança do que encontramos na área de estudo. São frações granulométricas que apresentam maior facilidade de serem erodidas, pois não possuem muita coesão, nem peso suficiente que dificulte a ação da água, tanto no processo de splash, como no escoamento superficial (Farmer, 1973; De Ploey, 1985, citado por Guerra et al., 1996).

Tendo em conta o conteúdo de matéria orgânica, De Ploey e Poesen (1985, citado por Guerra, 2007) referem que solos com menos de $2 \%$ de matéria orgânica possuem baixa estabilidade de agregados, enquanto Greenland et al. (1975, citado por Guerra, 2007) afirmam que solos com menos 3,5\% de matéria orgânica são instáveis, e que valores entre os percentuais apontados são preocupantes, no que diz respeito à capacidade dos solos de resistirem ao impacto das gotas de chuva. No caso de SBHAG, o teor de matéria orgânica dos solos na sua maioria é inferior a 2 e $3 \%$, uma vez que apenas uma amostra de solo teve matéria orgânica igual a 3\% (fig. 5 e 6 e TABELA III). Registaram-se ainda casos preocupantes de solos com matéria orgânica igual a 0,4\%, apresentando-se como solos suscetíveis à erosão.

Identificação dos processos erosivos na sub-bacia Hidrográfica de Água de Gato

A partir do trabalho de campo realizado procurouse identificar os diferentes tipos de formas de erosão presentes na SBHAG e analisar os fatores atuantes que desencadearam os processos erosivos ocorridos. Alguns desses processos erosivos foram identificados numa segunda etapa de trabalho de campo, ou seja, com ocorrência das precipitações.

Segundo Salomão (2007), havendo condições favoráveis ao escoamento superficial das águas, observa-se o transporte das partículas libertadas do solo por escoamento laminar ou difuso e concentrado, ou através de pequeno filetes, que, num estágio seguinte, por concentração de linhas de fluxo de água superfície do terreno, dá origem a sulcos (fot. 10).

É importante realçar que os processos erosivos desencadeados ocorrem com mais frequência no período húmido (Agosto a Outubro) por ação do escoamento 
TABELA III - Resultados das análises de textura e matéria orgânica dos solos amostrados na SBHAG.

TABLE III - Results of texture analysis and organic matter in the soil sampled in the SBHAG.

\begin{tabular}{|c|c|c|c|c|c|}
\hline Cod-mone & Areia (\%) & Limo (\%) & Argila (\%) & Classificação Textural & M. O. (\%) \\
\hline a1 & 41 & 57 & 1 & Limoso & 1,3 \\
\hline a2 & 23 & 75 & 0 & Limoso & 1,3 \\
\hline a3 & 36 & 61 & 1 & Limoso & 1,3 \\
\hline a5 & 28 & 58 & 15 & Franco Limoso & 1,5 \\
\hline a6 & 20 & 50 & 28 & Franco Argilo Limoso & 2,1 \\
\hline a7 & 21 & 76 & 1 & Limoso & 1,8 \\
\hline a8 & 21 & 77 & 1 & Limoso & 1,4 \\
\hline a9 & 28 & 50 & 19 & Franco Limoso & 2 \\
\hline a10 & 13 & 87 & 1 & Limoso & 1,5 \\
\hline a11 & 48 & 45 & 5 & Franco Limoso & 2,5 \\
\hline a12 & 63 & 26 & 10 & Franco Limoso & 1,8 \\
\hline a14 & 61 & 37 & 1 & Franco Limoso & 0,9 \\
\hline a15 & 26 & 65 & 11 & Limoso & 1,8 \\
\hline a16 & 23 & 65 & 14 & Franco Limoso & 2,9 \\
\hline a17 & 21 & 78 & 1 & Limoso & 1,7 \\
\hline a18 & 20 & 78 & 1 & Limoso & 1,7 \\
\hline a19 & 20 & 53 & 27 & Franco Argilo Limoso & 1,5 \\
\hline a20 & 47 & 53 & 1 & Limoso & 2,8 \\
\hline a21 & 61 & 40 & 1 & Limoso & 1 \\
\hline $\mathrm{a} 22$ & 36 & 64 & 0 & Limoso & 1,6 \\
\hline a23 & 52 & 48 & 0 & Limoso & 2 \\
\hline a24 & 33 & 69 & 1 & Limoso & 1,6 \\
\hline a26 & 48 & 53 & 0 & Limoso & 1,1 \\
\hline a28 & 26 & 57 & 19 & Franco Limoso & 1,3 \\
\hline a29 & 24 & 55 & 19 & Franco Limoso & 1,3 \\
\hline a30 & 34 & 58 & 11 & Limoso & 1,1 \\
\hline a31 & 44 & 49 & 8 & Limoso & 0,9 \\
\hline a34 & 32 & 58 & 11 & Limoso & 1,9 \\
\hline a35 & 66 & 32 & 0 & Franco Limoso & 2,6 \\
\hline a36 & 23 & 51 & 28 & Franco Limoso & 1,7 \\
\hline a37 & 35 & 54 & 11 & Limoso & 3 \\
\hline a38 & 14 & 53 & 37 & Franco Argilo Limoso & 2,9 \\
\hline a39 & 22 & 78 & 2 & Limoso & 2,4 \\
\hline a40 & 16 & 81 & 3 & Limoso & 2,4 \\
\hline $\mathrm{a} 41$ & 37 & 48 & 14 & Franco Limoso & 1,6 \\
\hline $\mathrm{a} 42$ & 54 & 43 & 2 & Franco Limoso & 1,5 \\
\hline a43 & 41 & 59 & 0 & Limoso & 1,2 \\
\hline $\mathrm{a} 44$ & 28 & 54 & 15 & Franco Limoso & 1,5 \\
\hline a45 & 35 & 51 & 11 & Franco Limoso & 1,2 \\
\hline a46 & 64 & 32 & 4 & Franco Limoso & 0,4 \\
\hline $\mathrm{a} 47$ & 70 & 31 & 0 & Franco Limoso & 1 \\
\hline a48 & 30 & 55 & 11 & Franco Limoso & 1,7 \\
\hline a49 & 30 & 59 & 9 & Limoso & 1,4 \\
\hline a50 & 40 & 47 & 10 & Franco Limoso & 2,3 \\
\hline a51 & 57 & 44 & 2 & Franco Limoso & 0,7 \\
\hline a52 & 19 & 68 & 17 & Franco Limoso & 1,5 \\
\hline
\end{tabular}

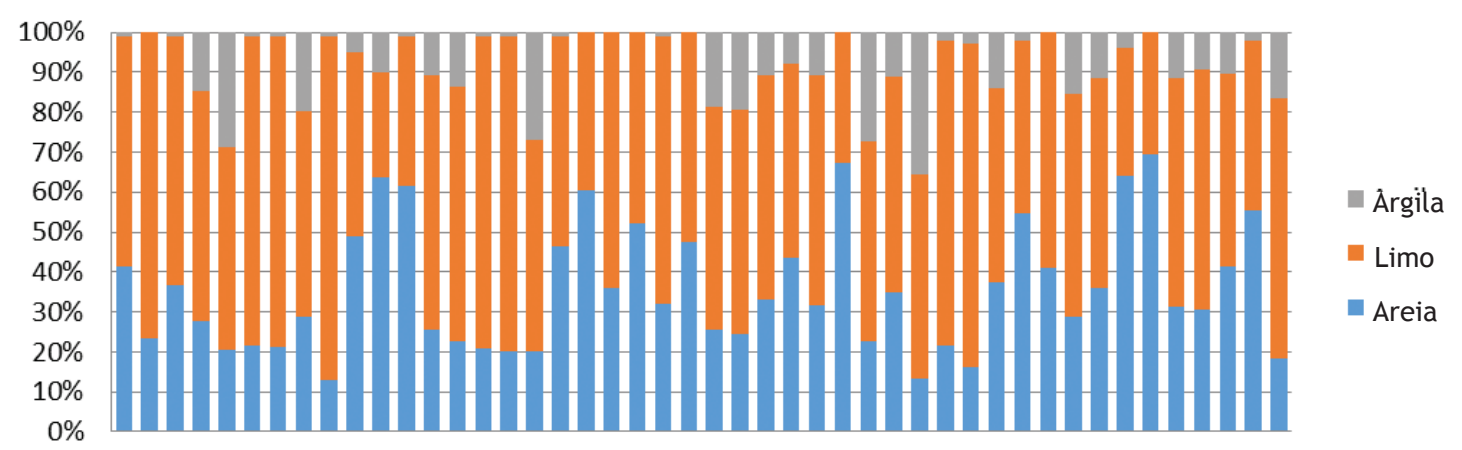

a1 a3 a6 a8 a10a12 a15 a17 a19 a21 a23 a26 a29 a31 a35 a37 a39 a41 a43 a45 a47 a49 a51

Fig. 5 - Variação percentual de Areia, limo e argila nos diferentes pontos amostrados na SBHAG. Fonte: LASAP, 2012.

Fig. 5 - Percentage variation of sand, silt and clay in the different sampling points in the SBHAG. Source: LASAP 2012. 
4

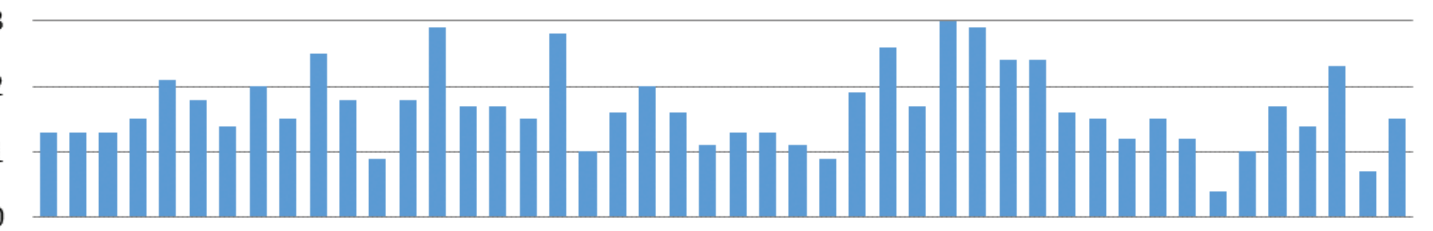

a1 a3 a6 a8 a10 a12 a15 a17 a19 a21 a23 a26 a29 a31 a35 a37 a39 a41 a43 a45 a47 a49 a51 - Mat. Org\%

Fig. 6 - Variação percentual de matéria orgânica nos diferentes pontos amostrados na SBHAG.

Fig. 6 - Percentage variation of organic matter in the different sampling points in the SBHAG.

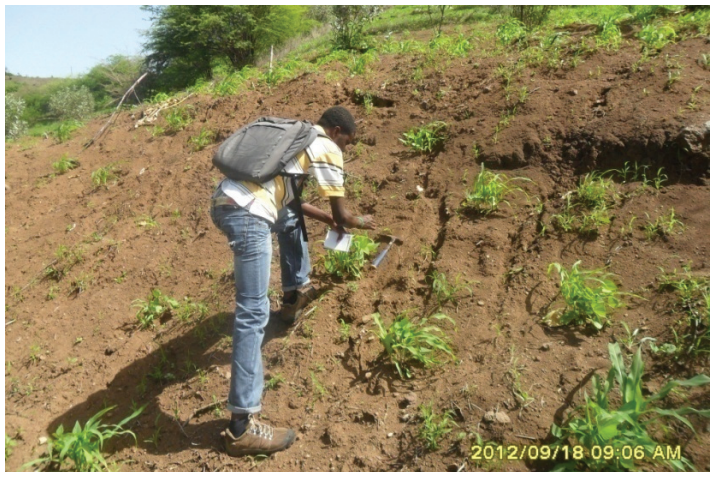

Fot. 10 - Erosão laminar seguida de erosão em sulcos, causada por concentração das linhas de fluxo das águas de escoamento superficial na zona de Pinha (Fonte: F. Sanches, 2012).

Photo 10 - Sheet wash followed by rill erosion caused by runoff concentration at Pinha's zone (Source: F. Sanches, 2012).

superficial, especialmente nos locais onde se verifica uma intensa atividade agrícola, deixando os solos mais suscetíveis a esses processos (fot. 11 e 12).

Numa primeira fase da erosão, regista-se o aumento do escoamento superficial decorrente de escoamento em lençol ou laminar, promovendo o transporte de sedimentos, e posteriormente passagem para erosão linear, nomeadamente em sulco, ravina e "barranco" (fot. 13, 14 e 15), que são estágios mais avançados da

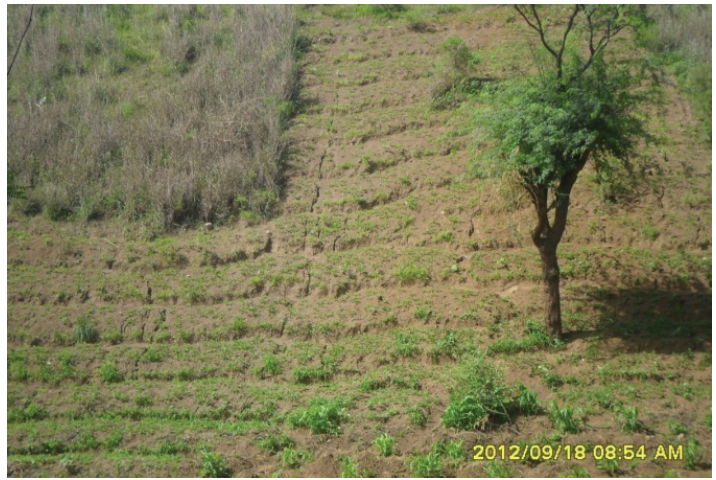

Fot. 11 - Erosão em sulcos associada a cultura em camalhões na zona de Figueira Branca (Fonte: F. Sanches, 2012).

Photo 11 - Rill erosion in a field with ridges at Figueira Branca's zone (Source: F. Sanches, 2012).

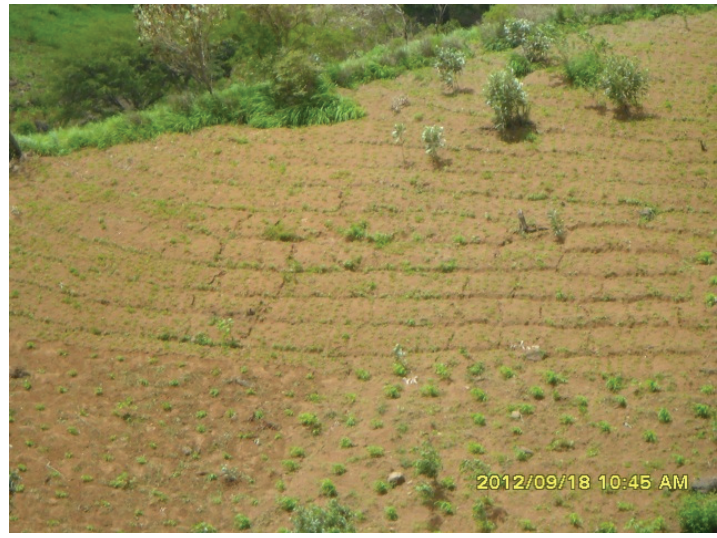

Fot. 12 - Erosão em sulcos associada a cultura em camalhões na zona de Pinha. Fonte: Autor, 2012.

Photo 12 - Rill erosion in a field with ridges at Pinha's zone (Source: F. Sanches, 2012).

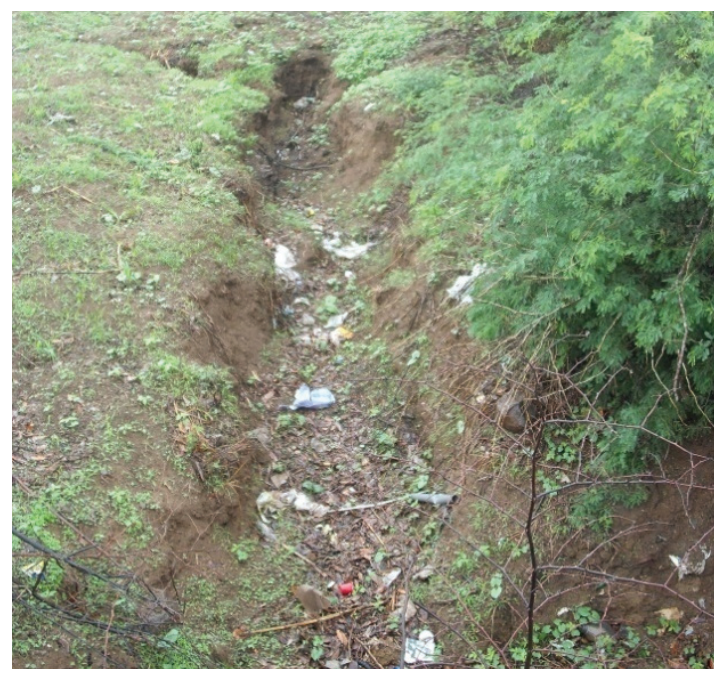

Fot. 13 - Erosão por ravinamento na zona de Covão de Engenho (Fonte: F. Sanches, 2012).

Photo 13 - Gully erosion at Covão de Engenho's zone (Source: F. Sanches, 2012).

erosão. No caso da ravina ilustrada na fotografia 14, ela está associada a corte de estrada, e formou-se na sequência de apenas um evento chuvoso. 


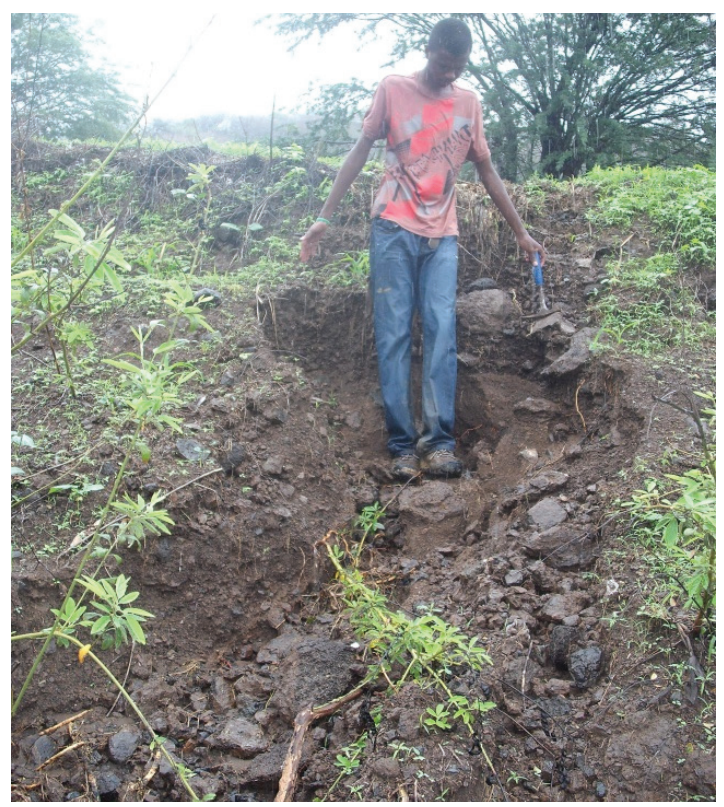

Fot. 14 - Erosão por ravinamento na zona de Pinha (Fonte: F. Sanches, 2012).

Photo 14 - Gully erosion at Pinha's zone (Source: F. Sanches, 2012).

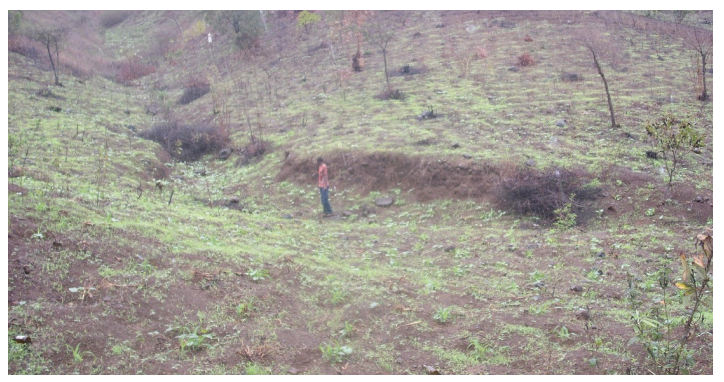

Fot. 15 - Desenvolvimento de "barrancos" na zona de Pinha (Fonte: F. Sanches, 2012).

Photo 15 - Gully erosion at Pinha's zone (Source: F. Sanches, 2012).

\section{Considerações finais}

O trabalho desenvolvido na SBHAG permitiu-nos inferir sobre os fatores envolvidos nos processos de erosão que ocorrem nas vertentes. Da análise feita na área de estudo foi possível chegar a algumas conclusões sobre os processos erosivos aí identificados.

Os solos amostrados indiciaram ser vulneráveis aos processos erosivos atuantes, por terem, na sua maioria, elevada percentagem de limo. Os solos com estas características são mais suscetíveis à erosão. A análise efetuada aos solos amostrados revelou também baixo teor de matéria orgânica, ou seja, abaixo de recomendada por diversos pesquisadores. Este aspeto torna-se mais dramático, porque na área em estudo se verifica sobretudo nas encostas onde se faz cultivo de sequeiro, reduzindo a incorporação de nutrientes necessários.
A declividade assume na SBHAG, também um papel importante, isto porqueem função dela, uma percentagem bastante significativa da área se apresenta propensa à ocorrência de processos erosivos, identificando-se cerca de $40 \%$ da área com declives superiores a $20 \%$ e mais de $38 \%$ com declives entre os 12 e os $20 \%$, criando, assim, condições para uma atuação mais acentuada da erosão hídrica por ação da escorrência superficial.

A precipitação é um dos elementos fundamentais no estudo dos processos erosivos na área de estudo, uma vez que a combinação deste fator com os fatores relacionados com o uso e gestão, as propriedades do solo, a vegetação e o declive, acaba por transformá-la num dos elementos mais importantes no desencadeamento dos processos erosivos.

No entanto, percebe-se que a ocorrência dos processos erosivos na área de estudo não é resultante apenas de fatores naturais (precipitação, declive, vegetação, etc.), mas também das atividades humanas desenvolvidas sobretudo nas encostas declivosas. Os resultados mostram que os processos erosivos afetam com uma certa severidade a área onde se pratica a agricultura de sequeiro, tendo sido encontrados vários indícios de degradação de solo, como transporte de sedimentos pela encosta abaixo, associadas à prática de capina (“monda”). Ainda associada à atividade humana, identificamos na área de estudo solos expostos a processos erosivos, fruto de remoção de coberto vegetal para alimentar o gado e preparação das parcelas para receber a nova sementeira, deixando assim os solos mais suscetíveis ao impacto das gotas da chuva. O fator antrópico assume, assim, um lugar de destaque, para não dizer de principal desencadeador dos processos erosivos nesta área.

Através do trabalho de campo foi possivel identificar uma serie de formas de erosão, como sulcos, sobretudo na época húmida, ravinas e, numa fase mais evoluída, os barrancos, que se encontram com alguma frequência na área.

Fazendo uma análise dos dados geoambientais, concluise existir uma significativa ocorrência de processos erosivos nas encostas da SBHAG, francamente suscetíveis a este tipo de fenómenos, em função dos diversos fatores enunciados ao longo do trabalho, quer decorrentes da dinâmica natural e das caraterísticas físicas da área, quer de natureza antrópica. Neste sentido, os resultados demonstram a necessidade de conhecer a dinâmica destas encostas face aos processos erosivos, de modo a prevenir impactes ambientais decorrentes da ação conjunta dos fenómenos naturais e antrópicos.

\section{Bibliografia}

Amaral, I. (1964). Santiago de Cabo Verde. A Terra e os Homens. Memórias de Junta de Investigações do Ultramar. N. ${ }^{\circ}$ 48. $2^{\text {a }}$ Série, Lisboa. 
Araújo, G. H., Almeida, J. R., \& Guerra, A. J. (2005). Gestão Ambiental de Áreas Degradadas. Rio de Janeiro, Brasil: Bertrand Brasil LTDA.

Carvalho, I. R. (2009). Monitoramento Ambiental da Estrada São Domingos-Assomada, Ilha de Santiago, Cabo Verde, Com Ênfase na Compartimentação Geomorfológica (Dissertação de Mestrado). Universidade Federal de Pernambuco, Recife.

Costa, C. D., Temóteo, A. D. e Zimback, R. C. (25-30 de Abril de 2009). Caracterização de uma bacia hidrografica quanto a suscetibilidade a erosão, utilizando técnicas de geoprecessamento. Anais XIV de Simpósio Brasileiro de Senso-riamento Remoto, p. 3689-3695.

Costa, F. L. (2004). Contribuiç̃̃oes para o conhecimento dos processos erosivos em Cabo Verde. Geoinova, 9, p. 195-221.

Costa, F. L. e Nunes, M. C. (2008). Susceptibilidade à erosão hídrica na Bacia de Ribeira Seca (Santiago, Cabo Verde). XI Colóquio Ibérico de Geografia, Alcalá de Henares.

Hernández, R., Semedo, J. M., Almeida, A. (2010). Manual de extensão rural e melhoria da produção agrícola. (F. V., Ed.) JICA/ DGASP - Componente Extensão Rural, Praia, Cabo Verde.

DGOTDU - DIRECÇÃO GERAL DO ORDENAMENTO DO TERRITÓRIO E DESENVOLVIMENTO URBANO (2003). Dados Cartográficos da Municípia. Praia, Cabo Verde.

Diniz, A. C. e Matos, G. C. (1986). Carta de Zonagem Agro-Ecológica e da Vegetação de Cabo Verde I-Ilha de Santiago. Lisboa, Instituto de Investigação Científica tropical.

COMISSÃO DAS COMUNIDADES EUROPEIAS (2002). Comunicação da Comissão ao Conselho, ao Parlamento Europeu, ao Comité Económico e Social das Regiões-Para uma estratégia Temática de Protecção do Solo, (p. 179). Bruxelas.

Faria, F. X. (1970). Os solos da ilha de Santiago. Junta de Investigações do Ultramar, Lisboa. Estudos, ensaios e documentos, 124, p. 157.

Ferreira, Denise de Brum (1987). La crise climatique actuelle dans l'archipel du Cap Vert. Quelques aspects du problème dans l'île de Santiago. Finisterra, 22 (43), Lisboa, p. 113-152.

Guerra, A. J.T. (s.d.). A erosão do solo no contexto social.

Guerra, A. J. T. (2007). O Início do Processo erosivo. In A. J. Guerra, A. S. Silva, \& R. G. Botellho, Erosão e Conservação dos Solos: conceitos, temas e aplicações ( $3^{\text {a }}$ ed., p. 340). Rio de Janeiro, Brasil: Bertrand Brasil Ltda.

Guerra, A. J. T. (1990). O Papel da Matéria Orgânica e dos Agregados na Erodibilidade dos Solos, Anuário do Instituto de Geociências, XIII, p. 43-52.
Guerra, A. J., e Botelho, R. G. (1996). Características e Propriedades dos Solos Relevantes Para os Estudos Pedológicos e Análise dos Processos Erosivos. Anuário de Instituto de Geociências, 19, p. 93-114.

Hernández, R. V. (2008). Caracterização dos solos da ilha de Santiago (Cabo Verde) numa perspectiva de sustentabilidade ambiental (Dissertação de Mestrado). Universidade de Aveiro, Departamento de Geociências, Aveiro.

INMG - INSTITUTO NACIONAL DE METEOROLOGIA E GEOFÍSICA. Dados pluviométricos de período de 2001 a 2010, posto de Lém Pereira - Concelho São Domingos.

Leal, A. B. (2008). Estudo da abordagem utilizada pelo DESIRE na problemática de degradação e desertificação das terras na bacia hidrográfica da Ribeira Seca. INIDA, Cabo Verde, p. 49.

MINISTÉRIO DO AMBIENTE AGRICULTURA E PESCAS (Dezembro de 2004). Livro Branco sobre o Estado do Ambiente em Cabo Verde.

Salomão, F. T. (2007). Controle e Preservação dos Processos Erosivos. In A. J. Guerra, A. S. Silva, e R. G. Botelho, Erosão e Conservação dos Solos: conceitos, temas e aplicações ( $3^{\text {a }}$ ed., p. 340). Rio de Janeiro, Brasil: Bertrand Brasil Ldat.

Sanches, F. G. (2012). Avaliação e Diagnósticos dos Processos Erosivos na Sub-Bacia Hidrpgráfica de Água Gato Concelho de São Domingos. Monografia, Universidade de Cabo Verde, Ciências e Tecnologia, Praia.

Serralheiro, A., Macedo, J. R. e Silva, L. C. (1976). Carta Geológica de Cabo Verde-Ilha de Santiago. Junta de Investigações Cientificas do Ultramar, Instituto Geográfico e Cadastral.

Sousa, S. C., Oliveira, V. P. e Oliveira, M. R. (2012). Solos, Uso de Terra e Sistema de Produção da ltha de Santiago do Arquilélago de Cabo Verde. In V. P. Oliveira , I. G. Gomes, I. Baptista, L. S. Rabelo, e A. Guimarães (Ed.), Cabo Verde: Análise Socioambiental e Perspectivas para o Desenvolvimento Sustentável em Áreas Semiáridas (p. 91-103). Fortaleza, brasil: UFC.

Tavares, J. P. (2010). Érosion des Sols au Cap Vert: Étude des Processus et Quantification à L'échelle de Trois Bassins Versants de L'île de Santiago (Tese de Doutoramento). Universiade de Bourgogne.

Tavares, J. P. e Amiotte-Suchet, P. (2012). Erosão Hídrica e Degradação de Terras em Cabo Verde. In V. P. Oliveira, I. G. Gomes, I. Baptista, e L. S. Rabelo, Cabo Verde: Análise Socioambiental e Perspectivas para o Desenvolvimento Sustentável em Áreas Semiáridas (p. 373). Fortaleza, Brasil. 